\title{
Diversity: How to Begin the Discussion
}

Brenda Alston-Mills, Michigan State University, USA

\begin{abstract}
The perception of diversity and inclusion, as it relates to social justice, often evokes destructive responses, either spoken or unspoken. It is one of the 'malicious problems' found in the classroom, the workplace, and amongst other parts of our society. In challenging these problems with diversity and inclusion, conversations regarding the substantive aspects of oppression and inequitable distribution of power of one group over another must be initiated to educate or expand the thinking of our modern day society. Formulating solutions from these conversations, willing individuals must be able to name the issue, analyze its impact, and enact a positive change, while acknowledging the difficulties in creating conversations of an issue that is in dire need of revelation. This report provides a non-controversial presentation, beginning with reasons for resistance, followed by survival strategies, and ending with pro-active strategies to establish dialogue and to allow for personal stories. Further discussion will analyze aggressive behavior, examine critical core values for an individual and organization, discuss positive and effective methods for combating mistreatment, and empowerment strategies to respond positively to oppression. Strategies for engaging an organization are included, such as how to use these tools to co-create a vision for a welcoming environment in organizations, while acknowledging the uncomfortable atmosphere that surrounds the topic of cultural change. Accepting that this uncomfortable environment stems from fear itself, fear is a viable part of the process towards trust and resolution.
\end{abstract}

Keywords: Diversity and Inclusion; Difficult Discussions; Strategies for Change

\section{INTRODUCTION}

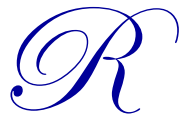

esistance is often encountered when the topic of diversity is introduced. One of the major factors identified by many people in the field is the recognition that systems are organized around privilege, those who have it and those who do not. The discomfort created by opening such discussions may be the result of guilt or the feeling of being blamed. As we look at racism, sexism, privilege, anti-Semitism, heterosexism, ablelism, dominance, and oppression, we recognize that language is important. We cannot talk about it if we are not willing to use the words. In addition, the problem is so deep and so wide; we have to be able to see it clearly that we can discuss it in useful ways. By such naming, it does not mean that we have created it. Part of the resistance is the fear that those words may somehow involve us (Johnson, 2008). People who have the power and control do not want to lose it. Dr. Beverly Tatum identified three forms of resistance, specifically as they relate to racism (Harvard Review, 1992). Since that date, four additional forms have been identified by the Opening Doors: A Personal and Professional Journey Workshop Facilitations Teams. ${ }^{1}$ Forms of resistance include:

1. Negative experiences in a past diversity workshop: These workshops operate on the principle of "shame and blame" rather than "teach and embrace". When the approach and content of a workshop invoke negative feelings, participants may be prevented from seeking out opportunities to learn about diversity.

2. Taboo about discussing differences in mixed groups: Most of us learned not to talk about difference to avoid creating tension. However, those in oppressed groups have fewer problems with such discussions compared to those groups with privilege and power.

\footnotetext{
${ }^{1}$ Opening Doors Diversity Project updated April 2011.

(C) 2012 The Clute Institute http://www.cluteinstitute.com/
} 
3. Denial of prejudice: We have tacitly acquired information about other groups without asking for it. All of us have received some form of prejudice. Denial of prejudice is also linked to the perception that people who hold these ideas are bad.

4. Thinking dichotomously: This concept leaves us with little choice. Thus, we fear being labeled "good or bad". One is either for or against rather than accepting a continuum regarding multiple perspectives. We suggest the use of 'and' rather than 'but'.

5. Myth of meritocracy: This belief, simply stated, is that anyone can make it if they work hard enough. It is based on the ideal of equal opportunity. Research shows us that unequal access to information and opportunity is not the reality for people in oppressed groups.

6. Inability to see ourselves as members of a dominant group and as part of the system: Because the world works for those with power and control, it alleviates the responsibility for the way the system does not work for everyone. The inherited system of advantage often disadvantages others.

7. For members of excluded groups, minimizing the extent and effect that discrimination has on the lives of people without power and privilege, can be a survival strategy. There is denial that discrimination occurs and belief that it has no effect on their individual lives.

These Forms of Resistance serve not only as a tool for self-reflection, but also as a tool to be aware of the resistance of others. Personal stories must be heard. Those who facilitate workshops in diversity and inclusion have employed several common methods. The first is pairing - there is one speaker and one listener. It is not a conversation or a dialogue. For a defined amount of time, the listener listens, and the speaker speaks; then they switch. A second method is to have focus groups that can either be random discussions of a specific topic or affinity groups where everyone shares a particular identity. Inner and outer circles are effective with the inner circle speaking on a particular issue while the outer circle listens. There may be the proviso that members of the outer circle can temporarily join the inner circle for further questions or thoughts. Whatever method is used, the goal of engaging in conversation around diversity is to provide a safe, trusting, and respectful environment for those stories to be heard (Anderson, 2008). We need to hear and exchange stories of the other's pain, sorrow, acknowledgement, confession, and apology (Good and Tally, 2000). To be effective, it is the responsibility of the listener to practice constructivist listening (Weissglass, 1998). The aims are to encourage reflection by the talker, such that the talker is able to work through feelings that may interfere with clear thinking. This mode of listening acknowledges the cognitive and affective processing that is needed for enhanced understanding. Constructivist listening is for the benefit of the talker to express his or her feelings and to release emotion if necessary (Weissglass, 1998).

\section{METHODOLOGY}

How does one create a safe space? For full participation, ground rules that include confidentiality are important to balance safety and risk (Landis 2008). All parties must have input to establish rules for engagement (Anderson, 2008). Drawing on a multiplicity of voices both present and not present (teachers, parents, those with experience) allows us to honor and welcome the voices of others. At the organizational level, all relevant and interested people are invited into the conversation (Whitney, Trosten-Bloom, 2010). How to begin? There are several strategies:

1. Find the common ground. Focus on commonalities among the participants of the group rather than the differences. One can then use the commonalities as a spring-board for the more difficult discussion around differences.

2. In a formal setting, such as a workshop, with today's technology, a facilitator can use photographs with directed questions to begin discussions. In contrast, random photographs can be employed with the participants having to relate the images to some aspect of diversity. Both function well.

3. Print media and videos are tools with the questions, 'How does it impact you?', 'What did you learn?', and 'What actions can I take?'

4. Role playing, case studies, and dramatic presentations can be employed with guided discussions.

5. The philosophy of Appreciative Inquiry (Cooperrider, 1987, and Easley, 2002) provides a novel and useful method of engaging in conversation. While recognizing the problem, Appreciative Inquiry focuses on the good and positive aspects of an issue and provides a way forward. In organizational change, Appreciative Inquiry provides for the co-creation of a vision for what the environment can be. For leaders, the more 
broadly one is able to think, the more accepting one is able to welcome diverse thoughts and feelings from others (Whitney, Trosten-Bloom, and Rader, 2010).

\section{METHODOLOGY USING IMAGES}

For short seminars, the use of domestic animals and wildlife in various situations offer a non-threatening method of getting everyone's attention. An example is the choice of a PowerPoint presentation of images using animals representing perceived aggression through reconciliation and relationship building. The facilitator should provide a series of questions to guide the discussion both during and after the presentation. Highlights are concepts of dominance, exclusion, survival behavior associated with being a victim, thriving and empowerment strategies, creativity and reflection.

\section{RESULTS AND EVALUATIONS}

The evaluation below is an assessment from two groups of undergraduate students participating in Leadership Development cohorts. Written questions were provided as prompts to promote conversations and discussions began in small groups followed by sharing as a large group. Below is a thumbnail of comments and evaluations (Figure 1).

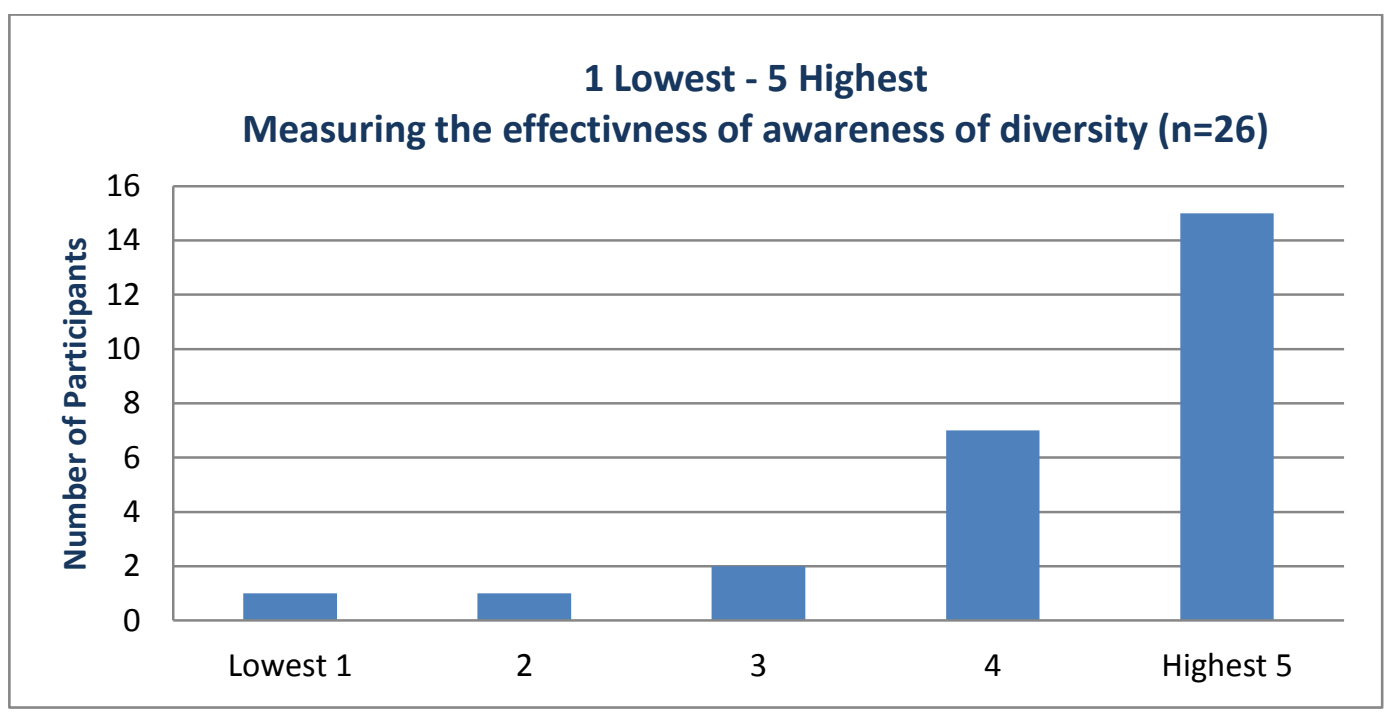

Figure 1: Summary of Evaluation Scores from Participants from the Leadership Development Groups

\section{COMMENTS}

1. Not much applicable advice other than to be aware of similarities

2. Did not pertain to leadership that well

3. Interesting comparison of human behavior and relationships with animals; good analogy to follow

4. Interesting and engaging presentation; I wasn't bored at any point

5. Very interactive and informative

6. Well thought out ideas and exaction of the material; Engaging and different without being lackluster

7. I loved the presentation and thought it was engaging and thought provoking.

8. Interesting and everyone can attend in it; Good presentation.

This type of presentation works for many and not all. For this reason, methodologies should be varied. 


\section{CONCLUSION}

In order to begin discussions on diversity, one must acknowledge the difficulty that exists for those with privilege to recognize that it is granted by nature of being born into a specific group. There are also privileges that can be chosen, such as religion, or acquired, such as the level of education. At the same time, it is acknowledged that there is not equal access to opportunity for all, especially for those not granted privilege by virtue of belonging to certain groups. In order to overcome the initial fear of new ideas and progression forward, there must be strategies for beginning those conversations in a safe and trusting environment. Resistance is normal and is a viable part of the process toward resolution and change.

\section{AUTHOR INFORMATION}

Brenda Alston-Mills serves as the Associate Dean and Director for the Office of Diversity and Pluralism, College of Agriculture and Natural Resources at Michigan State University. She lectures, conducts seminars, and has published on the topics of underrepresented groups and women in academia, especially in science. While at North Carolina State University together with others, she examined curriculum transformation as it related to diversity. She holds an M.S. and Ph.D. in Zoology from Michigan State University and is a Professor of Animal Science. E-mail: alstonmi@anr.msu.edu

\section{REFERENCES}

1. Anderson, J.A. (2008) Diversity through diversity and globalization. Stylus Publishing, Sterling, VA

2. Castania, K. (2010) Facilitator's manual/apprentice curriculum. Opening doors: A personal and professional journey. Second edition: Research foundation of SUNY, Brockport, NY

3. Cooperrider, D., \& Srivastva, S. (1987). Appreciative inquiry in organizational life. In R.W. Woodman \& W. A. Passmore (Eds.) Research in organizational change and development. JAI Press Inc. Greenwich, CT.

4. Easley, C.A. (2002). Appreciative inquiry...A viable component of diversity management? Proceedings: Midwest academy of management, 2002.

5. Landis, K. ed.U. Alaska Anchorage and Alaska Pacific University (2008). Start talking: Handbook for engaging in difficult dialogues in higher education. University of Alaska Anchorage and Alaska Pacific University, Anchorage, AK.

6. Good, N., Talley, C.(2000). Ending racism in America, one conversation at a time. 08/30/2011 http://www.emu.edu/cjp/publications/faculty-staff/nancy-good/ending-racism-in-america

7. Johnson, A. G., (2006). Privilege, power and difference. Second edition. McGraw-Hill, NY.

8. Tatum, B., (1992).Talking about race, learning about racism: The application of racial identity development theory in the classroom. Harvard Education Review, 62 (1-24).

9. Weissglass, J. (1998) Ripples of hope building relationships for educational change. Center for Educational Change in Mathematics and Science University of California, Santa Barbara, CA.

10. Whitney, D., Trosten-Bloom, A., Rader, K. (2010). Appreciative leadership. McGraw-Hill, NY. 